\title{
Immunohistochemical expression of BerEP4, CK7 and EMA in basal cell carcinoma of the skin
}

\section{Vladimír Bartoš}

\author{
Article Info \\ Martin's Biopsy Center, Ltd., Martin, \\ Slovakia. \\ For Correspondence: \\ Vladimír Bartoš \\ vladim.bartos@gmail.com \\ Received: \\ Accepted: \\ 17 November 2019 \\ 23 December 2019 \\ ISSN: 2224-7750 (Online) \\ 2074-2908 (Print) \\ DOI: 10.3329/bsmmuj.v12i4.43721
}

Keywords: Basal cell carcinoma; BerEP4 CK7; EMA; Skin

\section{Cite this article:}

Bartoš V. Immunohistochemical expression of BerEP4, CK7 and EMA in basal cell carcinoma of the skin. Bangabandhu Sheikh Mujib Med Univ J. 2019; 12: 163 66.

\section{Copyright:}

The copyright of this article is retained by the author(s) [Atribution CC-By 4.0]

Available at:

www.banglajol.info

A Journal of Bangabandhu Sheikh Mujib Medical University, Dhaka, Bangladesh

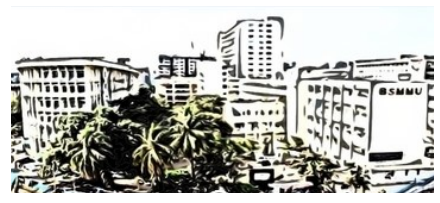

\section{Abstract}

The aim of this study was to evaluate the immunohistochemical expression status of BerEP4, EMA and CK7 in cutaneous basal cell carcinoma (BCC) and to find out whether there is some difference in the expression pattern related to the anatomic location of lesions. Biopsy specimens from 32 cases of BCC of the skin were enrolled. All samples were immunohistochemically stained for EpCAM (clone BerEP4), EMA (clone E29), and CK7 (clone OV-TL 12/30). All cases (32/32; 100\%) were strongly positive for BerEP4, while the vast majority of tumors $(28 / 32)$ were completely negative for EMA. Four BCCs (12.5\%) exhibited a focal staining for EMA, but it was only sporadic and did not exceed 5\% of tumor epithelium. Cytoplasmic expression of CK7 was found in 19 cases $(19 / 32 ; 59.4 \%)$. Comparing both, the chronically sun-exposed and the intermittently sun-exposed anatomic locations, the percentages of CK7-positive BCCs were 47.8 and $88.9 \%$, respectively. In conclusion, all lesions showed a strong expression of BerEP4, the use of this marker is helpful especially in individuals suspected of having multifocal BCC with many microlesions, morpheic BCC, or BCCs with mixed histomorphology.

\section{Introduction}

Basal cell carcinoma (BCC) of the skin is recently the most common malignancy in human population. 1 It exhibits a very heterogeneous histomorphology, on the basis of which it is classified into several subtypes and variants. 1 Despite of this variability, pathological diagnosis is usually not problematic and may be easily achievable from hematoxylin and eosin stained slides. However, in diagnostically difficult and challenging cases, an application of immunohistochemical methods is needed for a correct diagnosis. Immunohistochemistry is a technique that is being used to locate various antigens found on specific cells. Recently, it has become an important tool in medical research and serves as a companion in verifying differential diagnosis which cannot be determined by conventional analysis using hematoxylin and eosin staining. In routine dermatopathological practice, the two most important molecular markers in differential diagnosis of BCC are epithelial cell adhesion molecule/EpCAM (commonly termed BerEP4) and epithelial membrane antigen (EMA).$\underline{2,3}$ BerEP4 is a human glycoprotein located on the cell membrane and within the cytoplasm in the vast majority of epithelial cells, with the exception of squamous epithelium and mesothelium. EMA is a similar cell surface mucin glycoprotein, that is also produced in most epithelial cells. In general, cutaneous BCC is immunohistochemically positive for BerEP4 and negative for EMA. 2,3 This is in contrast with cutaneous squamous cell carcinoma, that is usually positive for EMA and negative for BerEP4.2,3 In addition, most BCCs are immunoreactive for cytokeratin 7 (CK7), but an expression of this marker is not constant. $\underline{4-6}$ A recent study $\underline{4}$ have postulated an interesting theory that cytokeratin profile of BCC may differ according to the degree of sun exposure and to the anatomical localization. It has demonstrated,,$\underline{4}$ CK7 expression was mostly present in non-photoexposed parts of the body. The goal of this study was to evaluate an immunohistochemical expression status of BerEP4, EMA and CK7 in cutaneous BCCs and to find out whether there is some difference in the expression pattern related to the anatomic location of lesions.

\section{Materials and Methods}

Biopsy samples from 32 primary BCCs of the skin were enrolled into this study. They were obtained from 28 patients ( 17 males, 11 females) in the age range of $36-89$ years (mean age 68.8 years). The histopathological subtypes of BCCs were as follows: superficial (3 cases), nodular (16 cases), mixed superficial-nodular (4 cases), mixed nodular-infiltrative (7 cases), and infiltrative ( 2 cases). The topographic locations of 
the lesions were merged into: a) chronically sunexposed body parts, and b) intermittently sunexposed body parts. The first category included the tumors located on the head (21 cases) and neck (2 cases). The second category comprised the tumors arising on the back ( 3 cases), chest ( 2 cases), shoulder (3 cases) and thigh (one case). Biopsy samples were routinely processed and all were simultaneously stained for EpCAM (mono-clonal mouse antihuman antibody, clone BerEP4, DAKO, ready-touse), EMA (monoclonal mouse anti-human antibody, clone E29, DAKO, ready-to-use), and CK7 (monoclonal mouse anti-human antibody, clone OV -TL 12/30, DAKO, ready-to-use) according to manufacturer's instructions. Positive reaction on epithelium of eccrine and sebaceous glands and on intact epidermis served as internal control.

\section{Results}

All the cases studied $(32 / 32 ; 100 \%)$ were strongly positive for BerEP4. Except for two BCCs, which showed an immunoreactivity in about $80 \%$ of tumor tissue, all other revealed a diffuse cytoplasmic and membranous positivity throughout the whole lesion (Figure 1A). The vast majority of cancers (28/32) were completely negative for EMA (Figure 1B). Four BCCs $(12.5 \%)$ exhibited a focal (cytoplasmic and membranous) staining for EMA, but it was only sporadic and did not exceed $5 \%$ of tumor epithelium. The EMA-reactive areas were confined to the periphery of tumor nests (Figure 1C), in which, interestingly, no feature of keratotic or squamoid differentiation was visible. Cytoplasmic expression of CK7 was found in 19 cases (19/32;

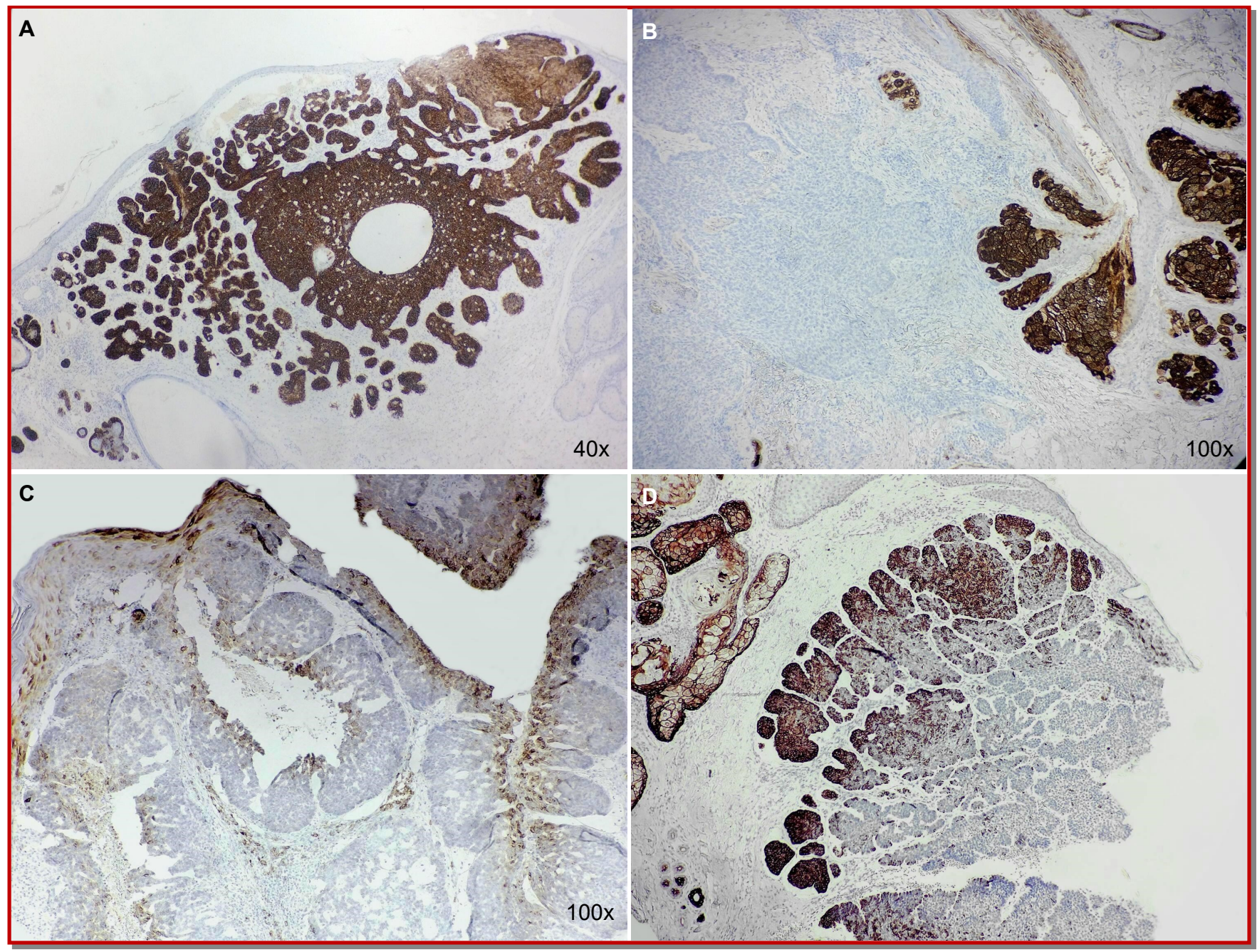

Figure 1: Difuse strong positivity of BerEP4 in nodular BCC (A); Negative immunostaining for EMA in nodular BCC (left part). Sebaceous glands and underlying epidermis (right part) are positive and serve as internal control. (magnification 100x) (B); Focal positivity for EMA in superficial-nodular BCC. Underlying intact epidermis (upper left part) is also positive (C); Focal positivity for CK7 in nodular BCC (in the centre). Sebaceous glands (left part) are also positive and serve as internal control (D) 
Table I

\begin{tabular}{|c|c|c|}
\hline $\begin{array}{r}\text { Immunol } \\
\text { accordin }\end{array}$ & $\begin{array}{l}\text { chemical expression of } \\
\text { chronically vs. interm }\end{array}$ & $\begin{array}{l}\text { 4, EMA and CK7 of BCCs } \\
\text { y sun-exposed body sites }\end{array}$ \\
\hline & Chronically sun-exposed & Intermittently sun-exposed \\
\hline BerEP4 & & \\
\hline Positive & $23 / 23(100 \%)$ & 9/9 (100\%) \\
\hline Negative & $0 / 23(0 \%)$ & $0 / 9(0 \%)$ \\
\hline EMA & & \\
\hline Positive & $2 / 23(8.7 \%)$ & $2 / 9(22.2 \%)$ \\
\hline Negative & 20/23 (91.3\%) & 6/9 (77.8\%) \\
\hline CK7 & & \\
\hline Positive & $11 / 23(47.8 \%)$ & $8 / 9(88.9 \%)$ \\
\hline Negative & $11 / 23(52.2 \%)$ & $0 / 9(11.1 \%)$ \\
\hline
\end{tabular}

$59.4 \%)$ and showed a wide quantitative range (10$100 \%$ of tumor tissue) (Figure 1D). Comparing both, the chronically sun-exposed and the intermittently sun-exposed anatomic locations, the percentages of CK7-positive BCCs were 47.8 and $88.9 \%$, respectively. A small number of the cases studied did not allow a statistical evaluation. A summary of the immunohistochemical findings in our set of BCCs is shown in Table I.

\section{Discussion}

This paper describes immunohistochemical expression status of three molecules, i.e. BerEP4, EMA and CK7 in a panel of 32 human BCCs of the skin. It has been demonstrated that BerEP4 is strongly positive in all BCCs, irrespective of the histological subtypes and topographic locations. This corroborates the results of many research done untill now. All but two studies have shown $3,6-10$ that this marker was highly expressed in all BCCs analyzed. The exceptions are the papers published by Ansai et al. (2012) 11 and Rajabi et al. (2007)2 In the study of Ansai et al. (2012) 11 among 31 BCCs, a single case (morpheic subtype) was BerEP4-negative. In the analysis of Rajabi et al. (2007)2 among 40 tumors, three (nodular, adenoid, and infiltrative subtype) were negative for BerEP4. This finding is very unusual and difficult to explain. I am of the opinion, those cases might represent a false (failure of immunohistochemical processing) rather than a true negativity.

Conversely, most of the published documents have found $3,6,8,12$ that all BCCs studied were uniformly negative for EMA. In the current paper, about 10\% of the BCCs displayed a focal staining for EMA, but in a very small quantity. Similar findings have been confirmed by some authors $2,7,13$ who had found a focal EMA reactivity in 5-8\% of BCCs.

As for CK7, the data are much less clear. Three studiest-6 have shown a positive staining in 57.7$77.8 \%$ of all BCCs, which is consistent with the present paper. However, some authors have observed,,- such as this study, CK7 expression showed differences depending on the BCC localization. In a study of García-de-la-Fuente et al. (2018) 4 the percentages of CK7-positive cases located on the face, the trunk, and the non-sun exposed parts of the body (such as vulva, axilla, perineum) were $53.3,81.8$, and $100 \%$, respectively. Obviously, there was the lowest proportion of the CK7-positive BCCs located on the skin permanently exposed to sunlight. Nevertheless, in 5 of 30 facial tumors, maximum levels of CK7 histoscore were detected, which suggests that different subsets of facial BCCs regarding CK7 expression may exist. In accord with the previous study,, it is observed in this study a lower percentage of the CK7-positive BCC cases arising on the chronically sun-exposed body parts $(47.8 \%)$ compared with the intermittently sun-exposed ones $(88.9 \%)$. It must be stressed, however, due to small number of the cases analyzed, the results are only indicative. Another intriguing finding has been reported by Alessi et al. (2008) 5 They showed, BCC with adnexal differentiation exhibited CK7 positivity in $88 \%$ of the cases, whereas in the other histologic subtypes, it was only in $42 \%$. They postulated a possible glandular origin of some CK7positive BCCs on the non-photoexposed areas. Based on these results it can not support such a theory, as none of the CK7-positive lesions showed features of adnexal differentiation. An overview of the results of immunohistochemical expression of BerEP4, EMA and CK7 extracted from individual studies published in the literature (including this study) is present in Table II.

\section{Conclusion}

As all lesions showed a strong expression of BerEP4, the use of this marker is helpful especially in individuals suspected of having multifocal BCC with many microlesions, morpheic BCC, or BCCs with mixed histomorphology. BerEP4 can also be used to better identify the tumor excision margins mainly in recurring BCCs or in those cases, in which an assessment of resection margins is not reliable from hematoxylin and eosin stained slides.

\section{References}

1. Bartos V, Adamicová K, Kullová M, Péc M. Basal cell carcinoma of the skin-biological behaviour of the tumor and a review of the most important molecular predictors of disease progression in pathological practice. Klin Onkol. 2011; 24: 8-17.

2. Rajabi P, Aboutalebdokht M, Heidarpour M, Asilian A, Rajabi F. Evaluation of diagnostic values of EMA and Ber-Ep4 in distinction between basal cell carcinoma and squamous cell carcinoma of the skin. Iranian J Pathol. 2007; 2: 7-10. 
Table II

Immunohistochemical expression of BerEP4, EMA and CK7 derived from the published studies

\begin{tabular}{|c|c|c|}
\hline References & Number of cases & Positive rate $(\%)$ \\
\hline \multicolumn{3}{|l|}{ BerEP4 } \\
\hline Rajabi et al., 2007 & $40 \mathrm{BCC}$ & $37 / 40(92.5)$ \\
\hline Ansai et al., 2012 & $31 \mathrm{BCC}$ & $30 / 31(96.7)$ \\
\hline Krahl and Sellheyer, 2007 & $\begin{array}{r}28 \text { BCC, sclerosing + } \\
\text { infiltrating }\end{array}$ & $28 / 28(100)$ \\
\hline Ishida et al., 2008 & $20 \mathrm{BCC}$ & $20 / 20(100)$ \\
\hline Beer et al., 2000 & $39 \mathrm{BCC}$ & $39 / 39(100)$ \\
\hline Fan et al., 2007 & $51 \mathrm{BCC}$, nodular & $51 / 51(100)$ \\
\hline Sramek et al., 2008 & 9 BCC, ocular & $9 / 9(100)$ \\
\hline Villada et al., 2018 & 10 BCC, head \& neck & $10 / 10(100)$ \\
\hline This study & $32 \mathrm{BCC}$ & $32 / 32(100)$ \\
\hline \multicolumn{3}{|l|}{ EMA } \\
\hline Rajabi et al., 2007 & $40 \mathrm{BCC}$ & $2 / 40(5.0)$ \\
\hline Beer et al., 2000 & $39 \mathrm{BCC}$ & $0 / 39(0)$ \\
\hline Fan et al., 2007 & $51 \mathrm{BCC}$, nodular & $4 / 51(8)$ \\
\hline Ramezani et al., 2016 & $29 \mathrm{BCC}$ & $0 / 29(0)$ \\
\hline Sramek et al., 2008 & 9 BCC, ocular & $0 / 9(0)$ \\
\hline Sinard, 1999 & $16 \mathrm{BCC}$, periorbital & $1 / 16(6.2)$ \\
\hline Villada et al., 2018 & 10 BCC, head \& neck & $0 / 10(0)$ \\
\hline This study & $32 \mathrm{BCC}$ & $4 / 32(12.5)$ \\
\hline \multicolumn{3}{|l|}{ CK7 } \\
\hline García-de-la-Fuente, 2018 & $67 \mathrm{BCC}$ & $49 / 67(73.1)$ \\
\hline Alessi et al., 2008 & $52 \mathrm{BCC}$ & $30 / 52(57.7)$ \\
\hline Sramek et al., 2008 & 9 BCC, ocular & $7 / 9(77.8)$ \\
\hline This study & $32 \mathrm{BCC}$ & $19 / 32(59.4)$ \\
\hline
\end{tabular}

3. Beer TW, Shepherd P, Theaker JM. BerEP4 and epithelial membrane antigen aid distinction of basal cell, squamous cell and basosquamous carcinomas of the skin. Histopathology 2000; 37: 218-23.

4. García-de-la-Fuente MR, Santacana M, Valls J, Vilardell F, Fernández Armenteros JM, Pujol R, Gari E, Casanova JM. Cytokeratin profile of basal cell carcinomas according to the degree of sun exposure and to the anatomical localization. Am J Dermatopathol. 2018; 40: 342-48.

5. Alessi E, Venegoni L, Fanoni D, Berti E. Cytokeratin profile in basal cell carcinoma. Am J Dermatopathol. 2008; 30: 249-55.

6. Sramek B, Lisle A, Loy T. Immunohistochemistry in ocular carcinomas. J Cutan Pathol. 2008; 35: 641-46.

7. Fan YS, Carr RA, Sanders DS, Smith AP, Lazar AJ, Calonje E. Characteristic Ber-EP4 and EMA expression in sebaceoma is immunohistochemically distinct from basal cell carcinoma. Histopathology 2007; 51: 80-86.

8. Villada G, Kryvenko ON, Campuzano-Zuluaga G, Kovacs C, Chapman J, Gomez-Fernandez C. A limited immunohistochemical panel to distinguish basal cell carcinoma of cutaneous origin from basaloid squamous cell carcinoma of the head and neck. Appl Immunohistochem Mol Morphol. 2018; 26: 126-31.

9. Krahl D, Sellheyer K. Monoclonal antibody Ber-EP4 reliably discriminates between microcystic adnexal carcinoma and basal cell carcinoma. J Cutan Pathol. 2007; 34: 782-87.

10. Ishida $M$, Kushima $R$, Okabe H. Immunohistochemical demonstration of D2-40 in basal cell carcinomas of the skin. J Cutan Pathol. 2008; 35: 926 $-30$.

11. Ansai S, Takayama R, Kimura T, Kawana S. BerEP4 is a useful marker for follicular germinative cell differentiation of cutaneous epithelial neoplasms. J Dermatol. 2012; 39: 688-92.

12. Ramezani M, Mohamadzaheri E, Khazaei S, Najafi F, Vaisi-Raygani A, Rahbar M, Sadeghi M. Comparison of EMA,CEA, CD10 and Bcl-2 bio-markers by immunohistochemistry in squamous cell carcinoma and basal cell carcinoma of the skin. Asian Pac J Cancer Prev. 2016; 17: 1379-83.

13. Sinard JH. Immunohistochemical distinction of ocular sebaceous carcinoma from basal cell and squamous cell carcinoma. Arch Ophthalmol. 1999; 117: 776-83. 